\title{
Efficacy of intra-arterial neoadjuvant chemotherapy through the superior epigastric artery in the treatment of locally advanced triple negative breast cancer
}

\author{
H. Y. JIN*, W. HE, Q. LIU, X. F. WANG, Y. F. LIU, Z. X. WEI \\ Department of Oncology, Puren Hospital, Wuhan, Hubei Province 430081, P. R. China \\ *Correspondence: qtw2015@szhtcm.org
}

Received September 18, 2015 / Accepted March 4, 2016

\begin{abstract}
Triple negative breast cancer (TNBC) is associated with aggressive behaviour and poor prognosis, but has limited treatment options. To explore novel and effective therapies against TNBC, we retrospectively analyzed the efficacy of neoadjuvant intraarterial chemotherapy through the superior epigastric artery in the treatment of locally advanced TNBC. Fifty-one locally advanced TNBC patients who received this neoadjuvant therapy from Mar 2001 to Mar 2012 were included in this study. The superior epigastric artery was selected for cannulation to deliver chemotherapy drugs. The regimen for intra-arterial chemoinfusion consisted of $75 \mathrm{mg} / \mathrm{m}^{2}$ epirubicin and $75 \mathrm{mg} / \mathrm{m}^{2}$ docetaxel. Clinical and pathological tumor responses, disease free survival (DFS), overall survival (OS), and toxicity profiles were recorded and retrospectively analyzed. In 51 patients treated with neoadjuvant intra-arterial chemoinfusion through the superior epigastric artery, the overall response rate (ORR) was 84.3\%; 16 patients achieved pathological complete response (pCR). Following surgical treatment and adjuvant chemotherapy, 5 -year DFS and OS were $72.4 \%$ and $75.9 \%$, respectively, in the study population. In addition, this neoadjuvant approach showed favorable toxicity profiles. Moreover, patients who achieved pCR showed a superior survival outcome compared with those who did not. Cox regression analysis indicated that Ki-67 expression is an independent predictor for DFS and OS. Our results suggest that intra-arterial chemotherapy through the superior epigastric artery has great therapeutic potential for the treatment of locally advanced TNBC. This approach merits further clinical evaluation and may become a novel therapeutic option for locally advanced TNBC.
\end{abstract}

Key words: intra-arterial infusion, superior epigastric artery, locally advanced triple negative breast cancer, Ki67 expression

Breast cancer is one of the most lethal diseases for women. It is a heterogeneous disease in which the presence of estrogen receptor (ER), progesterone receptor (PR), and human epidermal growth factor receptor 2 (HER2) signals can be used to construct molecular subtypes [1-3]. The subtype negative for $\mathrm{ER}, \mathrm{PR}$, and HER2 is defined as triple negative breast cancer (TNBC), which has a gene expression profile similar to basocellular breast cancer. However, TNBC is associated with

\footnotetext{
Abbreviations: AJCC - American Joint Committee on Cancer CI confidence interval DCR - disease control rate DFS - disease-free survival ECG - electrocardiogram ER - estrogen receptor HER2 - human epidermal growth factor receptor $2 \mathrm{HR}$ - hazard ratio IHC - immunohistochemistry MRI - magnetic resonance imaging ORR - overall response rate OS - overall survival PCR - pathological complete response PR - progesterone receptor RECIST - the response evaluation criteria for solid tumors SD - standard deviation TNBC - triple negative breast cancer
}

aggressive biological behavior and poor prognosis [4-6]. It can lead to an increased risk of recurrence and visceral metastasis, as well as a higher mortality rate. Moreover, treatment options for TNBC are quite limited due to the absence of targeting receptors $[7,8]$.

In recent years, neoadjuvant chemotherapy (also called primary or preoperative chemotherapy) has been increasingly used in patients with TNBC. The aim of neoadjuvant treatment is to reduce the size of unresectable tumors, thus allowing surgery to become an option for these patients [9]. Additionally, for patients with resectable tumors, neoadjuvant treatment decreases the need for mastectomy and increases the likelihood of breast conservation [10]. A number of studies have demonstrated that neoadjuvant chemotherapy is more beneficial for TNBC than for nonTNBC tumors [11]. For example, Liedtke et al. [12] reported 
that the rates of pathological complete response (pCR) were significantly higher with neoadjuvant treatment in patients with TNBC than in those with non-TNBC. Additionally, researchers found that in TNBC patients with pCR, neoadjuvant treatment is associated with improved overall survival (OS) as compared with adjuvant treatment [13]. Therefore, neoadjuvant chemotherapy has been accepted as a reliable treatment option for TNBC, especially in the locally advanced stages [14-16].

Intra-arterial infusion chemotherapy has been used as a neoadjuvant treatment for breast cancer since the 1960s [17, 18]. In this setting, chemotherapeutics can effectively reach the tumor tissue via cannulation of the dominant artery supplying the breast (e.g. the subscapular artery, or the lateral or internal thoracic arteries), and achieve a high local drug concentration, leading to enhanced anticancer effects as compared to conventional intravenous infusion $[19,20]$. Several studies have demonstrated the effectiveness of intra-arterial infusion in the treatment of breast cancer, with response rates ranging from $77.3 \%$ to $90 \%[21,22]$. Nevertheless, as far as we know, the majority of current cannulation procedures for intra-arterial chemoinfusion are performed through the femoral artery to the subclavian artery, which can cause the chemotherapeutic drugs to flow into the ipsilateral upper extremity, leading to severe complications such as atrophy and disability of the ipsilateral upper extremity [19]. Therefore, the cannulation procedure still needs to be improved in order to minimize the risk of complications and sequelae related to intra-arterial chemotherapy.

The superior epigastric artery, a terminal branch of the internal thoracic artery, is located outside the thoracic cavity and supplies the upper anterior part of the abdominal wall [23]. This artery is superficial as compared to the internal thoracic artery, and may represent an ideal potential target artery for intra-arterial chemoinfusion for breast cancer [24]. To date, however, there are few reports on the efficacy of intra-arterial chemoinfusion through this artery, especially in the treatment of locally advanced TNBC. In our clinical practice, we began cannulating the superior epigastric artery to perform intraarterial infusion in breast cancer patients in 2001. The present study was carried out in order to retrospectively evaluate the efficacy of this approach for patients with locally advanced TNBC.

\section{Patients and methods}

Setting and inclusion/exclusion criteria. In this study, we retrospectively reviewed a database of breast cancer patients who underwent intra-arterial neoadjuvant chemotherapy through the superior epigastric artery from Mar 2001 to Mar 2012 in the authors' institution. The study protocol complies with the principles of the Declaration of Helsinki and was approved by the institutional review board.

In order to ensure the quality of this retrospective study, strict inclusion and exclusion criteria were applied. Patients were included if they met the following criteria: (1) age $\geq 18$ years old; (2) female with newly-diagnosed primary, unilateral, non-metastasized breast cancer; (3) histologically confirmed TNBC; (4) histologically conformed locally advanced breast cancer (T3-4 any NM0 or any TN2M0) according to the American Joint Committee on Cancer (AJCC) staging manual ( $7^{\text {th }}$ edition); (4) adequate baseline hematologic, hepatic and renal functions; (5) no other malignant tumors; and (6) having detailed clinical and follow-up data available for review. Exclusion criteria were age less than 18 years, pregnancy, or breast-feeding.

Surgical procedures for intra-arterial chemoinfusion. The superior epigastric artery ipsilateral to the lesion was cannulated for intra-arterial chemoinfusion. In brief, a $6-\mathrm{cm}$ paramedian incision was made in the epigastrium, and dissection was carried down through the subcutaneous tissue. Then, the anterior layers of the rectus sheath were opened and approximately 1.5 to $2.0 \mathrm{~cm}$ of the superior epigastric artery was exposed. After distal ligation, a catheter (4F or 5F Cobra catheter (Cook Corporation, Bloomington, IN, USA)) was proximally inserted into the superior epigastric artery and advanced about $18-20 \mathrm{~cm}$. Afterwards, $2 \mathrm{ml}$ methylene blue solution ( $1 \%$, weight/volume) was injected through the catheter to optimize catheter advancement according to the extent of the staining. Complete staining of the skin overlying tumor lesions indicated the optimal position for the catheter. After the catheter was fixated, chemotherapeutic drugs were infused through the catheter using an infusion pump for a minimum of $20 \mathrm{~min}$. The regimen for intra-arterial chemoinfusion consisted of $75 \mathrm{mg} / \mathrm{m}^{2}$ epirubicin and $75 \mathrm{mg} / \mathrm{m}^{2}$ docetaxel in $50 \mathrm{ml}$ of normal saline. After the infusion was completed, the catheter was removed and the distal end of the superior epigastric artery was ligated in order to achieve a high drug concentration in the tumor and prevent leakage of the drugs.

Intra-arterial chemoinfusion was performed once every three weeks. Two weeks after the first infusion, primary lesions and involved lymph nodes were evaluated by ultrasound and magnetic resonance imaging (MRI) in all patients. Surgery (modified radical mastectomy or breast-conserving surgery) was carried out if there was both a significant improvement in the involvement of skin and muscle tissue and the primary lesion and regional lymph nodes had shrunken considerably in volume. Otherwise, patients were assigned to undergo another cycle of intra-arterial chemoinfusion. After surgery, adjuvant intravenous chemotherapy was administered for up to six cycles using the same regimen as for intra-arterial chemotherapy.

Immunohistochemical evaluation of Ki-67. Ki-67 expression in tumor tissues was detected by immunohistochemistry (IHC). Briefly, core needle biopsies ( $\geq 3$ representative specimens) were performed in all patients. The collected specimens were embedded in paraffin and sliced to $4 \mu \mathrm{m}$ in thickness, according to the routine method. Then, the prepared sections were fixed in $10 \%$ neutral formaldehyde solution and incubated with Ki-67 primary antibody after antigen retrieval 
(dilution: 1:100) (Boster Co. Ltd., Wuhan, China). Afterwards, sections were treated with a horseradish peroxidase (HRP)labeled secondary antibody and diaminobenzidine (DAB) kit (Boster Co. Ltd.), and counter-stained with hematoxylin.

For each patient, five high-power fields $(40 \times)$ containing at least 1000 tumor cells were randomly selected for semiquantitative IHC analysis. Cells with immunostaining in the nucleus were defined as Ki-67-positive cells. The percentage of Ki-67-positive cells was calculated by counting the number of Ki-67-positive cells and the total number of cells. A Ki-67 expression cut-off value of $20 \%$ was defined according to previous literature $[25,26]$.

Tumor response and toxicity assessment. Clinical tumor responses to intra-arterial chemotherapy were assessed based on ultrasound and MRI examinations according to the response evaluation criteria for solid tumors (RECIST 1.1) [27]. A pathological complete response (PCR) was defined as the

Table 1. Demographic characteristics of patients enrolled in this study

\begin{tabular}{|c|c|}
\hline Variable & $\begin{array}{l}\text { Intra-arterial chemoinfusion } \\
\qquad(\mathrm{N}=51)\end{array}$ \\
\hline \multicolumn{2}{|l|}{ Age } \\
\hline Mean age (years) a & $50.7 \pm 9.3$ \\
\hline$\leq 50(\mathrm{n}, \%)$ & $28(54.9)$ \\
\hline$>50(\mathrm{n}, \%)$ & $23(45.1)$ \\
\hline \multicolumn{2}{|l|}{ Menstrual status (n, \%) } \\
\hline Pre/peri-menopausal & $22(43.1)$ \\
\hline Postmenopausal & $29(56.9)$ \\
\hline \multicolumn{2}{|l|}{ Pathological status (n, \%) } \\
\hline Invasive ductal carcinoma & $47(92.2)$ \\
\hline Others & $4(7.8)$ \\
\hline \multicolumn{2}{|l|}{ Tumor stage (n, \%) } \\
\hline $\mathrm{T}_{2}$ & $7(13.7)$ \\
\hline $\mathrm{T}_{3}$ & $36(70.6)$ \\
\hline $\mathrm{T}_{4}$ & $8(15.7)$ \\
\hline \multicolumn{2}{|l|}{ Lymph node stage (n, \%) } \\
\hline $\mathrm{N}_{0}$ & $3(5.9)$ \\
\hline $\mathrm{N}_{1}$ & $22(43.1)$ \\
\hline $\mathrm{N}_{2}$ & $26(51.0)$ \\
\hline \multicolumn{2}{|l|}{ AJCC stage (n, \%) } \\
\hline IIB & $3(5.9)$ \\
\hline IIIA & $39(76.5)$ \\
\hline IIIB & $9(17.6)$ \\
\hline \multicolumn{2}{|l|}{ Primary tumor size (n, \%) } \\
\hline$\leq 5 \mathrm{~cm}$ & $19(37.3)$ \\
\hline$>5 \mathrm{~cm}$ & $32(62.7)$ \\
\hline \multicolumn{2}{|l|}{ Grade (n, \%) } \\
\hline 2 & $10(19.6)$ \\
\hline 3 & $41(80.4)$ \\
\hline \multicolumn{2}{|l|}{ Ki67 expression (n, \%) } \\
\hline$<20 \%$ & $24(47.1)$ \\
\hline$\geq 20 \%$ & $27(52.9)$ \\
\hline
\end{tabular}

${ }^{a}$ Data are presented as mean \pm SD

Abbreviations: AJCC, American Joint Committee on Cancer absence of residual invasive cancer in both the breast tissue and regional lymph nodes of the surgical specimen.

The toxicity of intra-arterial chemoinfusion was assessed at each cycle from the first day of the treatment until the day before surgery. Toxicity was monitored by routine physical examination, laboratory tests, and electrocardiogram (ECG); and classified according to the National Cancer Institute Common Terminology Criteria for Adverse Events, Version 4.03.

Follow-up. For all patients, follow-up was conducted every 3 to 4 months for the first 2 years, then every 6 months thereafter. Disease free survival (DFS) was measured from the date of diagnosis to the date of last follow-up, disease relapse (i.e. local and regional recurrence, distant metastases, or occurrence of secondary malignant neoplasms), or death. OS was calculated as the period from the date of diagnosis to the date of last follow-up or death.

Statistical analysis. All statistical analyses were performed using SPSS 13.0 software (SPSS Inc., Chicago, IL). Categorical data are expressed as counts and percentages. Continuous data are presented as means \pm standard deviations (SD). For survival data, Kaplan-Meier survival curves were plotted, and statistical differences were analyzed using the log-rank test. Univariate and multivariate logistic regression were performed to analyze the impact of the variables on the response rate of pCR. A Cox regression model was used to analyze the impact of the variables on patient survival. Hazard ratios (HR) were presented with their $95 \%$ confidence intervals (95\% CI). A value of $P<0.05$ was considered statistically significant (two-tailed).

\section{Results}

Demographic characteristics of patients. A total of 51 locally advanced TNBC patients who received intra-arterial chemoinfusion were eligible for this retrospective analysis during the study period. Their demographic characteristics are presented in Table 1. Forty-four patients $(86.3 \%)$ were diagnosed with T3 or T4 diseases, and 48 (94.1\%) were classified as AJCC stage III diseases. The mean tumor size was $9.7 \mathrm{~cm}$ in diameter. Skin and/or chest muscle involvement was seen in 14 patients (27.5\%), and axillary lymph node enlargement was found in 37 patients (72.5\%). Additionally, Ki-67 expression $<20 \%$ was seen in 24 patients (47.1\%).

Tumor response and toxicity assessment. All patients received surgical treatment after one cycle of intra-arterial chemoinfusion and were qualified for clinical and pathological response assessment. Tumor response results are summarized in Table 2. The overall response rate (ORR) and disease control rate (DCR) were $84.3 \%$ and $98.0 \%$, respectively. After intraarterial treatment, the mean tumor size of patients was $3.6 \mathrm{~cm}$ in diameter, which was significantly reduced as compared to pretreatment values. Additionally, symptoms in patients with skin and/or chest muscle involvement or with axillary lymph node enlargement showed improvements after intra-arterial chemoinfusion. Thirty-five patients received modified radical 


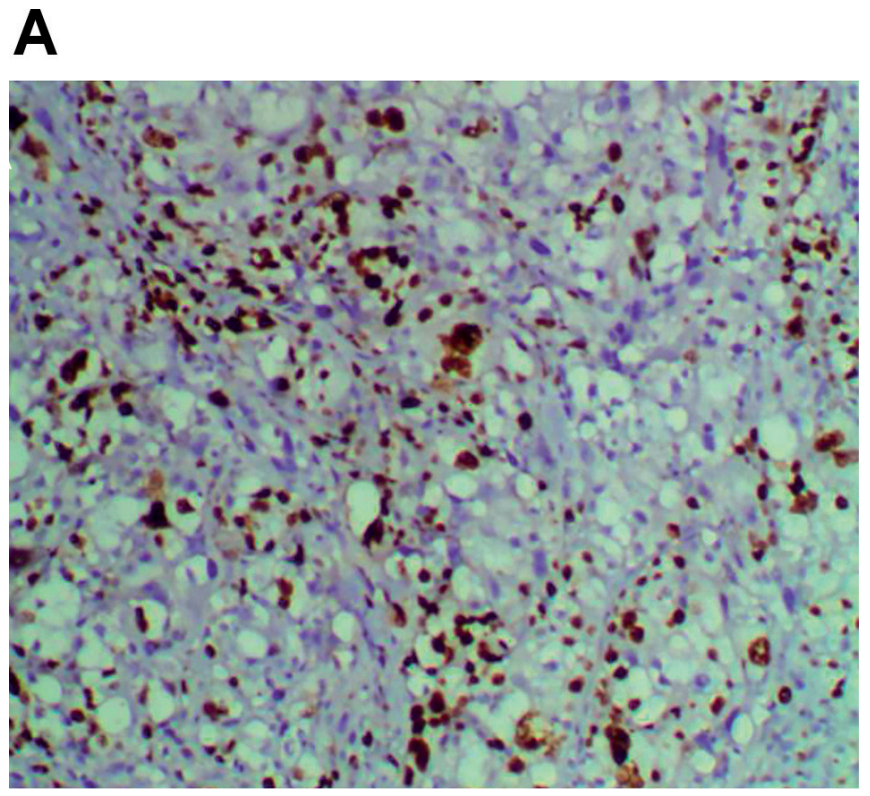

B

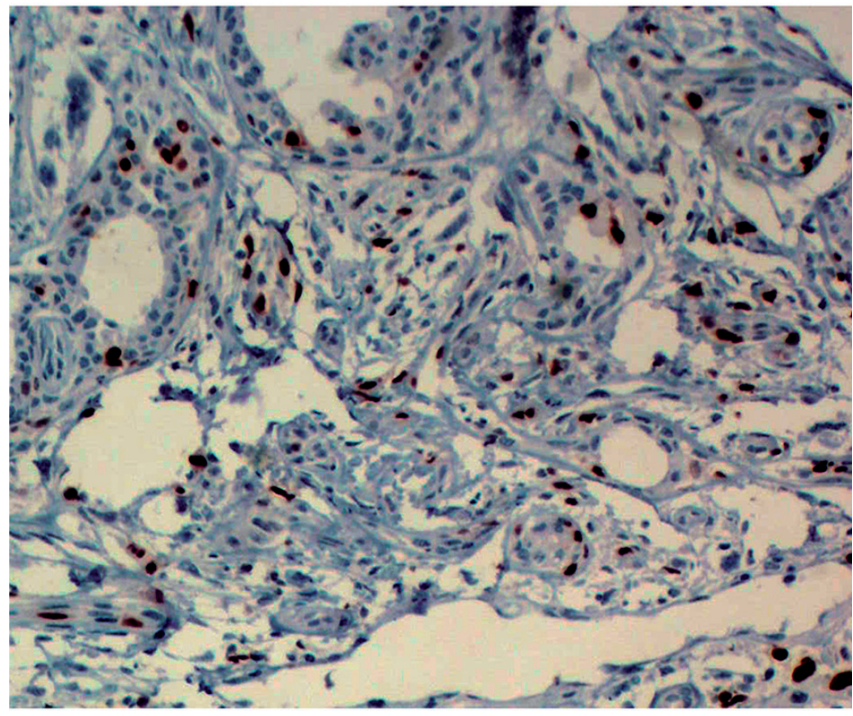

Figure 1. Representative IHC images of high and low Ki-67 expression. (A) A 57-year female patient with stage IIIA TNBC. IHC analysis showed a Ki-67 expression of 50\% in her tumor tissues. (B) A 63-female patient with stage IIIA TNBC. IHC analysis showed a Ki-67 expression of $15 \%$ in her tumor tissues. Magnification $=40 \times$.

mastectomy, while the rest received breast-conserving surgery. All surgeries were performed by experienced surgeons. The success rate of surgical resection was $100 \%$, and no patients developed severe intra- or post-operative complications. After surgery, 16 patients achieved pCR. Both univariate and multivariate analysis showed that Ki-67 expression was an independent predictor for $\mathrm{PCR}$ (Tables 3 and 4), indicating that patients with high Ki-67 expression ( $\geq 20 \%)$ were more sensitive to intra-arterial chemotherapy (representative IHC images of high and low Ki-67 expression are shown in Figure 1)

The toxicity profiles of intra-arterial chemoinfusion are listed in Table 5. It should be noted that skin ulceration was the most frequent toxicity found in this study $(21.6 \%, 11$ out of 51). Two patients (3.9\%) even experienced grade $3 / 4$ skin ulcerations, which were resolved by treatment with appropriate topical care. Other toxicities included gastrointestinal, hematologic, and cardiac disorders. However, these adverse events were mild (grade 1/2) and well-tolerated by patients, or were able to be controlled after 3 - 5 days of symptomatic treatment.

Survival outcomes. After surgery, 32 patients received three cycles of intravenous adjuvant chemotherapy, 14 patients received four cycles, and 5 patients received five cycles. After a median follow-up of 100.6 months (33.6 - 162.7 months), 13 patients $(25.5 \%)$ died of breast cancer-related causes, all of which had stage III tumors. Kaplan-Meier curves for DFS and OS are shown in Figure 2. Five-year DFS and OS rates were $72.4 \%$ and $75.9 \%$, respectively. Moreover, patients who achieved $\mathrm{pCR}$ showed a superior survival outcome compared with those who did not. In the pCR population, recurrence and disease-related death occurred in 2 (12.5\%, 2 out of 16$)$ and 1 cases $(6.3 \%, 1$ out of 16$)$, respectively; while in the non-pCR population, disease recurrence and death occurred in $14(40.0 \%, 14$ out of 35$)$ and 12 cases $(34.3 \%, 12$ out of 35$)$, respectively. Survival analysis demonstrated that patients with pCR were associated with significantly better DFS [107.7 months vs. 85.1 months, $\mathrm{HR}=0.25$ (95\% CI: $0.13-0.97$ ), $P=0.044]$ and $\mathrm{OS}$ [108.2 months vs. 89.8 months, $\mathrm{HR}=0.15$ (95\% CI: $0.09-0.92$ ), $P=0.036$ ], as compared to non-pCR patients (Figure 3 ). Cox regression analysis indicated that Ki67 expression $\geq 20 \%$ was an independent predictor for DFS $[P$

Table 2. Clinical and pathological responses to intra-arterial chemoinfusion

\begin{tabular}{lc}
\hline Tumor response & $\begin{array}{c}\text { Intra-arterial chemoinfusion } \\
\mathbf{( N = 5 1 )}\end{array}$ \\
\hline Clincial response (n, \%) & \\
CR & $17(33.3)$ \\
PR & $26(51.0)$ \\
SD & $7(13.7)$ \\
PD & $1(2.0)$ \\
ORR (n, \%) & $43(84.3)$ \\
DCR (n, \%) & $50(98.0)$ \\
Pathological response (n, \%) & \\
pCR & $16(31.3)$ \\
Non-pCR & $35(68.6)$ \\
\hline
\end{tabular}

Abbreviations: CR, complete response; $\mathrm{PR}$, partial response; $\mathrm{SD}$, stable disease; $\mathrm{PD}$, pregressive disease; $\mathrm{ORR}$, overall response rate; $\mathrm{DCR}$, disease control rate; pCR, pathological complete response 

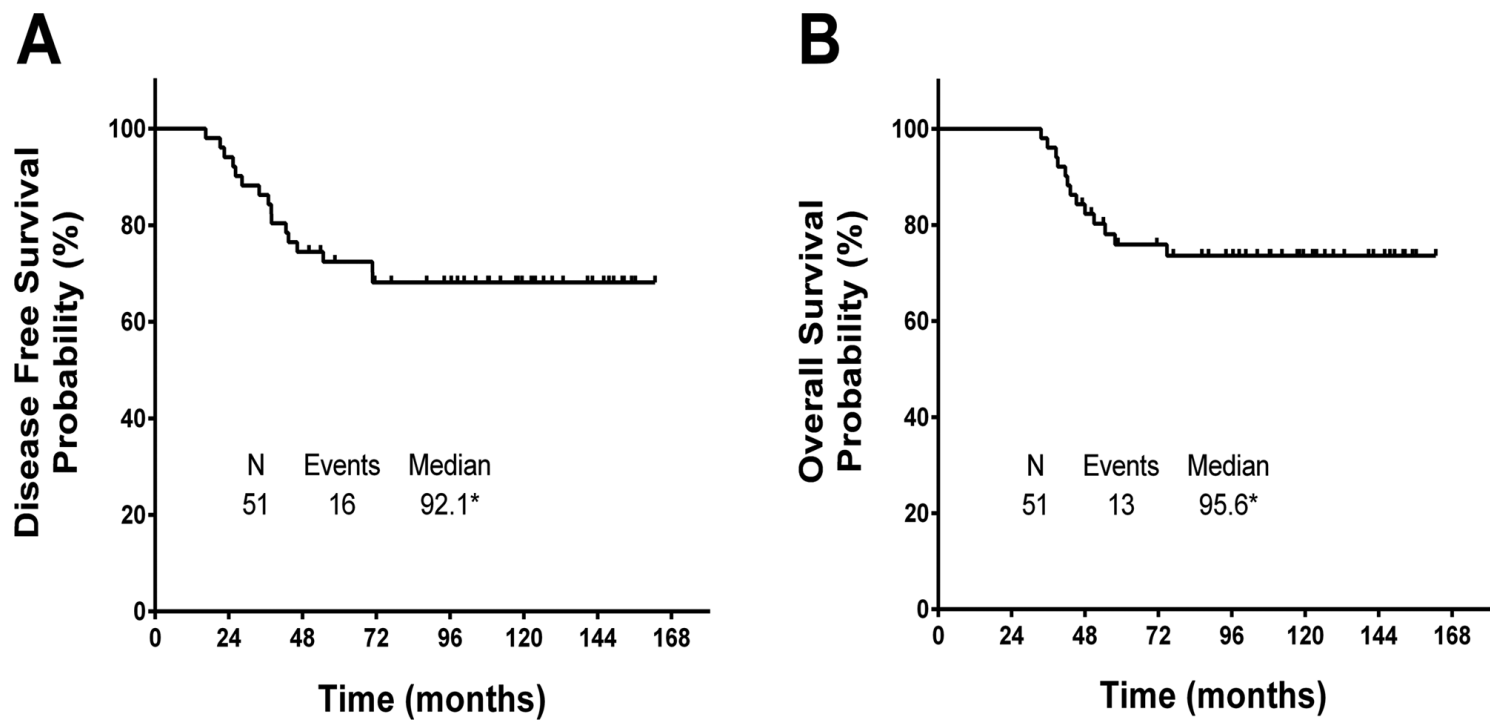

Figure 2. Kaplan-Meier curves for DFS (A) and OS (B) in 51 locally advanced TNBC patients who received neoadjuvant chemoinfusion through the superior epigastric artery. Asterisk $\left(^{*}\right)$ indicates mean survival time because median survival time could not be estimated due to data censorship $\geq 50 \%$.

Table 3. Univariate analysis of the association between patient characteristics and pathological response

\begin{tabular}{|c|c|c|c|}
\hline Variable & $\begin{array}{c}\text { pCR } \\
(\mathrm{N}=16)\end{array}$ & $\begin{array}{c}\text { Non-pCR } \\
(\mathrm{N}=35)\end{array}$ & $P$ value \\
\hline Age & & & 0.951 \\
\hline$\leq 50(\mathrm{n}, \%)$ & 7 & 16 & \\
\hline$>50(\mathrm{n}, \%)$ & 9 & 19 & \\
\hline Menstrual status (n, \%) & & & 0.504 \\
\hline Pre/peri-menopausal & 8 & 14 & \\
\hline Postmenopausal & 8 & 21 & \\
\hline Pathological status (n, \%) & & & 0.775 \\
\hline Invasive ductal carcinoma & 15 & 32 & \\
\hline Others & 1 & 3 & \\
\hline Tumor stage (n, \%) & & & 0.200 \\
\hline $\mathrm{T}_{2}$ & 1 & 6 & \\
\hline $\mathrm{T}_{3}$ & 14 & 22 & \\
\hline $\mathrm{T}_{4}^{3}$ & 1 & 7 & \\
\hline Lymph node stage (n, \%) & & & 0.281 \\
\hline NO & 0 & 3 & \\
\hline N1 & 9 & 13 & \\
\hline N2 & 7 & 19 & \\
\hline AJCC stage (n, \%) & & & 0.351 \\
\hline IIB & 1 & 2 & \\
\hline IIIA & 14 & 25 & \\
\hline IIIB & 1 & 8 & \\
\hline Primary tumor size (n, \%) & & & 0.756 \\
\hline$\leq 5 \mathrm{~cm}$ & 5 & 14 & \\
\hline$>5 \mathrm{~cm}$ & 11 & 21 & \\
\hline Grade (n, \%) & & & 0.387 \\
\hline 2 & 2 & 8 & \\
\hline 3 & 14 & 27 & \\
\hline Ki67 expression & & & 0.006 \\
\hline$<20 \%$ & 3 & 21 & \\
\hline$\geq 20 \%$ & 13 & 14 & \\
\hline
\end{tabular}

Abbreviations: pCR, pathological complete remission; AJCC, American Joint Committee on Cancer
$=0.046, \mathrm{HR}=0.28$ (95\% CI: $0.08-0.98)]$ and OS $[P=0.031$, $\mathrm{HR}=0.22(95 \%$ CI: $0.06-0.87)]$.

\section{Discussion}

This study was a single center, retrospective study with the purpose of investigating the efficacy of intra-arterial neoadjuvant chemotherapy through the superior epigastric artery in the treatment of locally advanced TNBC. For the 51 patients treated using this approach, the ORR was $84.3 \%$ (33.3\% CR and $51.0 \%$ PR); 16 patients achieved pCR. Following surgical treatment and adjuvant chemotherapy, 5-year DFS and OS in the study population were $72.4 \%$ and $75.9 \%$, respectively. In addition, intra-arterial chemotherapy through the superior epigastric artery showed favorable toxicity profiles. Taken together, our results suggest that this neoadjuvant approach has great therapeutic potential for the treatment of locally advanced TNBC.

As compared with other subtypes of breast cancer, treatment options for TNBC are limited due to the absence of drug-targetable receptors $[7,8]$. Nevertheless, a number of studies have demonstrated that TNBC responds well to cytotoxic chemotherapy, commonly having higher $\mathrm{pCR}$ rates than those found in other breast cancer subtypes [25]. Neoadjuvant chemotherapy is a well-established approach to the treatment of locally advanced TNBC, which reduces the size of unresectable tumors, thereby allowing surgical intervention to be performed [28]. In the neoadjuvant setting, chemotherapeutic agents are conventionally administered by intravenous infusion. Despite impressive response rates, however, conventional neoadjuvant therapy is associated with high local recurrence rates (up to $38 \%$ ) and high toxicity profiles [29]. In addition, researchers reported that a high proportion of patients with 

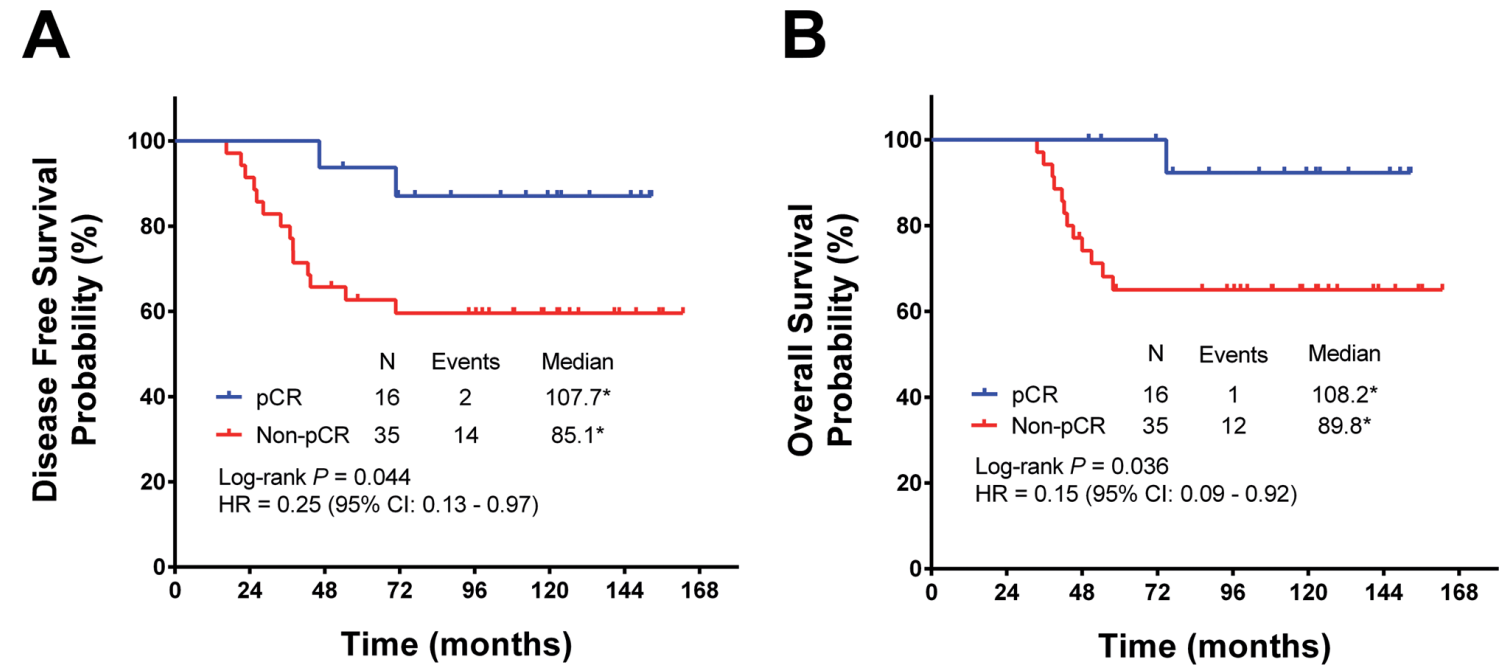

Figure 3. Kaplan-Meier curves for DFS (A) and OS (B) in intra-arterial chemoinfusion-treated patients stratified by pCR status. The statistical difference between the two survival curves was assessed using the log-rank test. HRs were calculated using a Cox regression model. Asterisk ( $\left.{ }^{\star}\right)$ indicates mean survival time because median survival time could not be estimated due to data censorship $\geq 50 \%$.

Table 4. Multivariate analysis of the association between patient characteristics and pathological response

\begin{tabular}{|c|c|c|c|c|c|}
\hline Variable & B & S.E. & Wald & $P$ value & $\operatorname{Exp}(B)(95 \% C I)$ \\
\hline Age & 0.121 & 0.788 & 0.023 & 0.878 & $1.128(0.241-5.286)$ \\
\hline Menstrual status & 0.354 & 0.758 & 0.218 & 0.641 & $1.425(0.322-6.298)$ \\
\hline Pathological status & 1.043 & 1.568 & 0.443 & 0.506 & $2.838(0.131-61.291)$ \\
\hline Tumor stage & -0.552 & 0.677 & 0.665 & 0.415 & $0.576(0.153-2.171)$ \\
\hline Lymph node stage & -0.292 & 0.613 & 0.226 & 0.634 & $0.747(0.225-2.484)$ \\
\hline AJCC stage & -0.358 & 0.851 & 0.177 & 0.674 & $0.699(0.132-3.705)$ \\
\hline Primary tumor size & 1.137 & 0.813 & 1.955 & 0.162 & $3.117(0.633-15.334)$ \\
\hline Grade & -0.107 & 1.021 & 0.011 & 0.916 & $0.898(0.121-6.647)$ \\
\hline Ki67 expression & 2.394 & 0.918 & 6.800 & 0.009 & $10.960(1.812-66.278)$ \\
\hline
\end{tabular}

Abbreviations: B, Beta coefficient; S.E., standard error; CI, confidence interval; AJCC, American Joint Committee on Cancer

locally advanced TNBC had poor prognoses after conventional neoadjuvant therapy due to failure to control local micrometastases of the tumor [30]. Therefore, in order to gain effective local control of micrometastasis, regional chemotherapy via intra-arterial infusion has been developed and evaluated in a number of clinical studies [9]. Table 6 summarizes the recent published results (within 10 years) regarding the outcomes of intra-arterial chemoinfusion in the treatment of breast cancer.

The major advantage of intra-arterial chemotherapy lies in the fact that it can achieve a relatively high drug concentration and retention in primary tumor tissues and involved lymph nodes, consequently improving anti-cancer efficacy and reducing the occurrence of side effects in normal tissues [31]. Additionally, in this setting, regionally administered chemotherapeutic agents can return to tumor tissues through blood
Table 5. Toxicity profiles of the intra-arterial chemoinfusion through the superior epigastric artery

\begin{tabular}{lcc}
\hline Toxicity & All grades & Grades 3/4 \\
\hline Gastrointestinal disorders & 2 & 0 \\
$\quad$ Nausea & 3 & 0 \\
$\quad$ Vomiting & & \\
Hematologic toxicities & 1 & 0 \\
$\quad$ Leukopenia & 2 & 0 \\
$\quad$ Neutropenia & 1 & 0 \\
$\quad$ Thrombocytopenia & & \\
Cardiac disorders & 1 & 0 \\
$\quad$ Heart failure & & \\
Skin and subcutaneous tissue disorders & 6 & 0 \\
$\quad$ Alopecia & 11 & 2 \\
$\quad$ Skin ulceration & & \\
\hline
\end{tabular}


Table 6. Literature review of the outcomes of intra-arterial chemoinfusion in the treatment of breast cancer within ten years

\begin{tabular}{|c|c|c|c|c|c|c|}
\hline $\begin{array}{l}\text { Author, year } \\
\text { (reference) }\end{array}$ & $\begin{array}{c}\text { Total number of } \\
\text { cases }\end{array}$ & $\begin{array}{l}\text { Stage/TNBC } \\
\text { status }\end{array}$ & $\begin{array}{l}\text { Artery for } \\
\text { cannulation }\end{array}$ & Regimen & Response & $\begin{array}{l}\text { Long-term } \\
\text { outcomes }\end{array}$ \\
\hline $\begin{array}{c}\text { Pacetti, et al. } 2006 \\
{[22]}\end{array}$ & 10 & $\begin{array}{c}9 \text { stage IIIB + } 1 \\
\text { stage IV/3 TNBC }\end{array}$ & the femoral artery & $\begin{array}{c}5-\mathrm{Fu}+\mathrm{EPI}+\mathrm{MMC}(\mathrm{by} \\
\text { bolus infusion) }\end{array}$ & $8 \mathrm{PR}+2 \mathrm{SD}$ & $\begin{array}{c}5 \text { DOD, OS: } 33.5 \\
\text { months }\end{array}$ \\
\hline $\begin{array}{l}\text { He, et al. } 2011 \\
{[32]}\end{array}$ & 24 & $\begin{array}{l}14 \text { stage II, } 6 \text { stage } \\
\text { III, and } 4 \text { stage } \\
\text { IV/24 TNBC }\end{array}$ & the femoral artery & $\mathrm{CTX}+\mathrm{EPI}+5-\mathrm{Fu}$ & $\begin{array}{l}9 \mathrm{CR}(4 \mathrm{pCR})+13 \\
\mathrm{PR}+1 \mathrm{SD}+1 \mathrm{PD}\end{array}$ & $\begin{array}{l}9 \text { DOD within } \\
\text { two years }\end{array}$ \\
\hline $\begin{array}{c}\text { Wang, et al } 2013 \\
{[19]}\end{array}$ & 53 & $\begin{array}{l}10 \text { stage IIIA, } 24 \\
\text { stage IIIB, and } 19 \\
\text { stage IIIC }\end{array}$ & the femoral artery & $\begin{array}{c}18 \mathrm{CTX}+\mathrm{EPI}+5-\mathrm{Fu} / 2 \\
\mathrm{EPI} \text { alone/ } 22 \mathrm{CTX} \\
+\mathrm{EPI}+\mathrm{Tax} / 10 \mathrm{TAX} \\
\text { alone/1 EPI + 5-Fu }\end{array}$ & $\begin{array}{c}7 \mathrm{CR}+41 \mathrm{PR}+ \\
5 \mathrm{SD}\end{array}$ & N/A \\
\hline Current study & 51 & $\begin{array}{l}3 \text { stage IIB, } 39 \text { stage } \\
\text { IIIA, and } 9 \text { stage } \\
\text { IIIB/51 TNBC }\end{array}$ & $\begin{array}{l}\text { the superior } \\
\text { epigastric artery }\end{array}$ & $\mathrm{EPI}+\mathrm{DCX}$ & $\begin{array}{c}17 \mathrm{CR}(16 \mathrm{pCR})+ \\
26 \mathrm{PR}+7 \mathrm{SD}+1 \mathrm{PR}\end{array}$ & $\begin{array}{c}13 \text { DOD, 5-year } \\
\text { DFS and OS rates: } \\
72.4 \% \text { and } 75.9 \%\end{array}$ \\
\hline
\end{tabular}

TNBC, triple negative breast cancer; 5-Fu, 5-fluorouracil, EPI, epirubicin; MMC, mitomycin; TAX, paclitaxel; DCX, docetaxel; CR, complete response; PR, partial response; SD, stable disease; PD, pregressive disease; pCR, pathological complete response; DOD, died of disease, OS, overall survival; DFS, diseasefree survival; N/A, not available

circulation, thus exerting a "second-hit" impact on tumors. In this study, intra-arterial chemoinfusion through the superior epigastric artery achieved an ORR of $84.3 \%$ and a pCR rate of $31.3 \%$, which are similar or even superior to the effects seen in standard intravenous neoadjuvant chemotherapy or intraarterial chemoinfusion through the femoral artery [19, 22, 32] (Table 6). Furthermore, long-term follow-up data showed that 5-year DFS and OS were $72.4 \%$ and $75.9 \%$, respectively, in the study population. Collectively, these data, at least in part, reflect the effectiveness of this intra-arterial therapy in controlling locally advanced TNBC.

Accumulating evidence from a series of clinical studies reveals that $\mathrm{pCR}$ is a predictive marker for clinical response, recurrence, and survival in TNBC patients [33, 34]. Consistently, in our study, survival analysis showed that patients who achieved pCR showed better DFS and OS rates than those who did not. However, it should be noted that PCR was defined as lacking any residual disease in both the breast tissue and axillary lymph nodes; otherwise, significant predictive errors may occur. In addition, IHC analysis indicated a significant association between $\mathrm{Ki}-67$ expression in tumor tissues and the occurrence of pCR. Ki-67, initially identified by Gerdes et al [35], is a nuclear protein associated with cell proliferation. Although there is still some debate, many studies have demonstrated the predictive value of Ki-67 regarding responsiveness to chemotherapy in breast cancer $[36,37]$. Particularly, Fasching et al. [38] have reported that Ki67 serves as an independent predictor for $\mathrm{PCR}$ in a group of breast cancer patients receiving neoadjuvant treatment. In accordance with these findings, the present study also found that when patients were treated with intra-arterial chemotherapy through the superior epigastric artery, most cases achieving pCR had a high level of Ki-67 expression. This may be attributed to the fact that high Ki67 expression generally reflects increased proliferation, whereas breast cancer cells with a high proliferation rate are usually sensitive to chemotherapy [39]. Additionally, Cox regression analysis showed that Ki-67 expression $\geq 20 \%$ was an independent predictor for DFS and OS. Taken together, these results suggest that Ki-67 expression can also be used as an independent factor for predicting prognoses of locally advanced TNBC patients treated using this neoadjuvant approach.

With regard to the toxicity profile, low incidence of gastrointestinal, hematological, and cardiac toxicity was observed using intra-arterial chemoinfusion through the superior epigastric artery. Moreover, as compared with other intra-arterial chemoinfusion procedures, cannulation through the superior epigastric artery can help to prevent serious upper extremity complications caused by leakage of chemotherapeutic drugs into the ipsilateral upper extremity. Nevertheless, it should be noted that skin ulceration was the most frequent toxicity related to this neoadjuvant chemoinfusion, which may be attributed to accidental leakage of epirubicin into the surrounding tissue. Hence, the surgical procedures, as well as treatment regimens such as dosing and schedule, should be further optimized in order to minimize treatment-related toxicity.

Several limitations of the present study should be addressed. The main limitation is its retrospective nature, which may have introduced inherent selection biases. Another limitation is the small population size and single ethnicity, which may limit the generalizability of the findings of this study. In addition, the lack of a control group limits interpretation of the results and prevents us from drawing any firm conclusions.

In summary, our data demonstrate the significant efficacy and safety of intra-arterial neoadjuvant chemotherapy through the superior epigastric artery in the treatment of newly-diagnosed locally advanced TNBC. This study provides supportive evidence that this neoadjuvant approach has great therapeutic potential for locally advanced TNBC and is most likely suitable for cases with higher Ki-67 expression. Thus, this treatment 
merits further clinical evaluation and may become a novel therapeutic option for locally advanced TNBC.

Acknowledgments: All authors would like to thank Ms. Rebekah Burdyshaw for her kind assistance in proofreading this manuscript.

\section{References}

[1] CUSTODIO A, MORENO-RUBIO J, APARICIO J, GALLEGO-PLAZAS J, YAYA R et al. Pharmacogenetic predictors of severe peripheral neuropathy in colon cancer patients treated with oxaliplatin-based adjuvant chemotherapy: a GEMCAD group study. Ann Oncol 2014; 25: 398-403. http://dx.doi. org/10.1093/annonc/mdt546

[2] PARK SB, GOLDSTEIN D, KRISHNAN AV, LIN CS, FRIEDLANDER ML et al. Chemotherapy-induced peripheral neurotoxicity: A critical analysis. CA Cancer J Clin 2013; doi: 10.1002/caac.21204.

[3] PARK SB, LIN CS, KIERNAN MC. Nerve excitability assessment in chemotherapy-induced neurotoxicity. J Vis Exp 2012; doi: 10.3791/3439. http://dx.doi.org/10.3791/3439

[4] EXTRA JM, MARTY M, BRIENZA S, MISSET JL. Pharmacokinetics and safety profile of oxaliplatin.Semin Oncol 1998; 2 Suppl 5: 13-22.

[5] HALLER DG. Safety of oxaliplatin in the treatment of colorectal cancer. Oncology (Williston Park) 2000; 12 Suppl 11: $15-20$.

[6] BECOUARN Y, YCHOU M, DUCREUX M, BOREL C, BERTHEAULT-CVITKOVIC F et al. Phase II trial of oxaliplatin as first-line chemotherapy in metastatic colorectal cancer patients. Digestive Group of French Federation of Cancer Centers. J Clin Oncol 1998; 16: 2739-2744.

[7] BUGAT R. Oxaliplatin tolerance in the treatment of metastatic colorectal cancers. Bull Cancer 2001; 88: S45-S49.

[8] CHOI J, KONG K, MOZAFFAR T, HOLCOMBE RF. Delayed oxaliplatin-associated neurotoxicity following adjuvant chemotherapy for stage III colon cancer. Anticancer Drugs 2006; 17: 103-105. http://dx.doi.org/10.1097/01. cad.0000185185.64980.70

[9] GAMELIN L, BOISDRON-CELLE M, MOREL A, GAMELIN E. Oxaliplatin neurotoxicity. Bull Cancer 2006; 93 Suppl 1: S17-S22.

[10] CASSIDY J, MISSET JL. Oxaliplatin-related side effects: characteristics and management. Semin Oncol 2002; 5 Suppl 15: 11-20. http://dx.doi.org/10.1053/sonc.2002.35524

[11] MAS MOREY P, CHOLVI LLOVELL M, NIGORRA CARO M, NICOLAS PICO J, VILANOVA BOLTO M. Oxaliplatinassociated neurotoxicity in clinical practice. Farm Hosp 2012; 36: 336-342. http://dx.doi.org/10.1016/j.farma.2011.03.010

[12] JARDIM DL, RODRIGUES CA, NOVIS YA, ROCHA VG, HOFF PM. Oxaliplatin- related thrombocytopenia. Ann Oncol 2012; 23: 1937-1942. http://dx.doi.org/10.1093/annonc/ mds074

[13] LAND SR, KOPEC JA, CECCHINI RS, GANZ PA, WIEAND HS et al. Neurotoxicity from oxaliplatin combined with weekly bolus fluorouracil and leucovorin as surgical adjuvant chemotherapy for stage II and III colon cancer: NSABP C-07.
Clin J Oncol 2007; 25: 2205-211. http://dx.doi.org/10.1200/ ICO.2006.08.6652

[14] BEIJERS AJ, MOLS F, VREUGDENHIL G. A systematic review on chronic oxaliplatin-induced peripheral neuropathy and the relation with oxaliplatin administration. Support Care Cancer 2014; 22: 1999-2007. http://dx.doi.org/10.1007/ s00520-014-2242-Z

[15] GENT P, MASSEY K. An overview of chemotherapy-induced peripheral sensory neuropathy, focusing on oxaliplatin. Int J Palliat Nurs 2001; 7: 354-359. http://dx.doi.org/10.12968/ ijpn.2001.7.7.9020

[16] MCWHINNEY SR, GOLDBERG RM, MCLEOD HL. Platinum neurotoxicity pharmacogenetics. Mol Cancer Ther 2009; 8: 10-16. http://dx.doi.org/10.1158/1535-7163.MCT08-0840

[17] COURNEDE A, RIES P, RICHARD K, GUILLAIN A, DAHAN L et al. Oxaliplatin neurotoxicity: a report of three cases with post-operative exacerbation. Gastroenterol Clin Biol 2005; 29: 461-464. http://dx.doi.org/10.1016/S0399-8320(05)80817-6

[18] GORNET JM, SAVIER E, LOKIEC F, CVITKOVIC E, MISSET JL et al. Exacerbation of oxaliplatin neurosensory toxicity following surgery. Ann Oncol 2002; 13: 1315-1318. http://dx.doi.org/10.1093/annonc/mdf254

[19] CAROZZI VA, CANTA A, CHIORAZZI A, CAVALETTI G. Chemotherapy-induced peripheral neuropathy: What do we know about mechanisms? Neurosci Lett 2014; [Epub ahead of print].

[20] PARK SB, LIN CS, KRISHNAN AV, GOLDSTEIN D, FRIEDLANDER ML et al. Utilizing natural activity to dissect the pathophysiology of acute oxaliplatin-induced neuropathy. Exp Neurol 2011; 227: 120-127. http://dx.doi.org/10.1016/j. expneurol.2010.10.002

[21] PARK SB, LIN CS, KRISHNAN AV, GOLDSTEIN D, FRIEDLANDER ML et al. Dose effects of oxaliplatin on persistent and transient $\mathrm{Na}+$ conductances and the development of neurotoxicity. PloS one 2011; 6: e18469. http://dx.doi.org/10.1371/ journal.pone.0018469

[22] PARK SB, KRISHNAN AV, LIN CS, GOLDSTEIN $\mathrm{D}$, FRIEDLANDER $\mathrm{M}$ et al. Mechanisms underlying chemotherapy-induced neurotoxicity and the potential for neuroprotective strategies. Curr Med Chem 2008; 15: 30813094. http://dx.doi.org/10.2174/092986708786848569

[23] KRISHNAN AV, GOLDSTEIN D, FRIEDLANDER M, KIERNAN MC. Oxaliplatin and axonal $\mathrm{Na}+$ channel function in vivo. Clin Cancer Res 2006; 12: 4481-4484. http://dx.doi. org/10.1158/1078-0432.CCR-06-0694

[24] OH SJ. Clinical electromyography: nerve conduction studies. 3rd ed. Baltimore: Lippincott, Williams \& Wilkins 2003.

[25] ARGYRIOU AA, POLYCHRONOPOULOS P, ICONOMOU G, KOUTRAS A, MAKATSORIS T et al. Incidence and characteristics of peripheral neuropathy during oxaliplatin-based chemotherapy for metastatic colon cancer. Acta Oncol 2007; 46: 1131-1137. http://dx.doi. org/10.1080/02841860701355055

[26] KRISHNAN AV, GOLDSTEIN D, FRIEDLANDER M, KIERNAN MC. Oxaliplatin-induced neurotoxicity and the 
development of neuropathy. Muscle Nerve 2005; 32: 51-60. http://dx.doi.org/10.1002/mus.20340

[27] SPROWL JA, CIARIMBOLI G, LANCASTER CS, GIOVINAZZO H, GIBSON AA et al. Oxaliplatin-induced neurotoxicity is dependent on the organic cation transporter OCT2. Proc Natl Acad Sci USA 2013; 110: 11199-11204. http://dx.doi.org/10.1073/pnas.1305321110

[28] VELASCO R, BRUNA J, BRIANI C, ARGYRIOU AA, CAVALETTI G et al. Early predictors of oxaliplatin-induced cumulative neuropathy in colorectal cancer patients. J Neurol Neurosurg Psychiatry 2014; 85: 392-398. http://dx.doi. org/10.1136/jnnp-2013-305334

[29] PARK SB, LIN CS, KRISHNAN AV, GOLDSTEIN D, FRIEDLANDER ML et al. Oxaliplatin-induced neurotoxicity: changes in axonal excitability precede development of neuropathy. Brain 2009; 132: 2712-2723. http://dx.doi. org/10.1093/brain/awp219

[30] PARK SB, LIN CS, KRISHNAN AV, GOLDSTEIN D, FRIEDLANDER ML et al. Long-term neuropathy after oxaliplatin treatment: challenging the dictum of reversibility. Oncologist 2011; 16: 708-716. http://dx.doi.org/10.1634/ theoncologist.2010-0248

[31] BRIANI C, ARGYRIOU AA, IZQUIERDO C, VELASCO R, CAMPAGNOLO $\mathrm{M}$ et al. Long-term course of oxaliplatininduced polyneuropathy: a prospective 2-year follow-up study. J Peripher Nerv Sys 2014; 19: 299 -306. http://dx.doi. org/10.1111/jns.12097

[32] TAIEB S, TRILLET-LENOIR V, RAMBAUD L, DESCOS L, FREYER G. Lhermitte sign and urinary retention: atypical presentation of oxaliplatin neurotoxicity in four patients. Cancer 2002; 94: 2434-2440. http://dx.doi.org/10.1002/cncr. 10500

[33] OTTAIANO A, NAPPI A, TAFUTO S, NASTI G, DE DIVITIIS C et al. Diabetes and body Mass Index are associated with neuropathy and prognosis in colon cancer patients treated with capecitabine and oxaliplatin adjuvant chemotherapy. Oncology 2016 [Epub ahead of print]. http://dx.doi. org/10.1159/000442527

[34] SHAHRIANI-AHMADI A, FAHIMI A, PAYANDEH M, SADEGHI M. Prevalence of oxaliplatin-induced chronic neuropathy and influencing factors in patients with colorectal cancer in Iran. Asia Pac J Cancer Prev 2015; 16: 7603-7606. http://dx.doi.org/10.7314/APJCP.2015.16.17.7603

[35] ARGYRIOU AA, BRIANI C, CAVALETTI G, BRUNA J, ALBERTI $P$ et al. Advanced age and liability to oxaliplatin-induced peripheral neuropathy: post hoc analysis of a prospective study. Eur J Neurol 2013; 20: 788-794. http:// dx.doi.org/10.1111/ene.12061

[36] ARGYRIOU AA, CAVALETTI G, ANTONACOPOULOU A, GENAZZANI GG, BRIANI C et al. Voltage-gated sodium channel polymorphisms play a pivotal role in the development of oxaliplatin-induced peripheral neurotoxicity: results from a prospective multicenter study. Cancer 2013; 119: 3570-3577. http://dx.doi.org/10.1002/cncr.28234

[37] RUZZO A, GRAZIANO F, GALLI F, GIACOMINI E, FLORIANI I et al. Genetic markers for toxicity of adjuvant oxaliplatin and fluoropyrimidines in the phase III TOSCA trial in high-risk colon cancer patients. Sci Rep 2014; doi: 10.1038/ srep06828. http://dx.doi.org/10.1038/srep06828

[38] TERRAZZIONO S, ARGYRIOU AA, CARGNIN S, ANTONACOPOULOU AG, BRIANI C et al. Genetic determinants of chronic oxaliplatin-induced peripheral neurotoxicity: a genome-wide study replication and meta-analysis. J Peripher Nerv Syst 2015; [Epub ahead of print]. http://dx.doi. org/10.1111/jns. 12110

[39] IBRAHIM A, HIRSCHFELD S, COHEN MH, GRIEBEL DJ, WILLIAMS GA et al. FDA drug approval summaries: oxaliplatin. Oncologist 2004; 9: 8-12. http://dx.doi.org/10.1634/ theoncologist.9-1-8

[40] HOFF PM, SAAD ED, COSTA F, COUTINHO AK, CAPONERO R et al. Literature review and practical aspects on the management of oxaliplatin-associated toxicity. Clin Colorectal Cancer 2012; 11: 93-100. http://dx.doi.org/10.1016/j. clcc.2011.10.004

[41] AROTCARENA R, CALES V, BERTHELEMY P, PARENT Y, MALET $M$ et al. Severe sinusoidal lesions: a serious and overlooked complication of oxaliplatin-containing chemotherapy? Gastroenterol Clin Biol 2006; 30: 1313-1316. http:// dx.doi.org/10.1016/S0399-8320(06)73542-4

[42] SAIF MW. Hypersensitivity reactions associated with oxaliplatin. Expert Opin Drug Saf 2006; 5: 687-694. http://dx.doi. org/10.1517/14740338.5.5.687

[43] MASON JM, REES GJ. Oxaliplatin-induced acute thrombocytopenia. J Oncol Pharm Pract 2011; 17: 433-435. http:// dx.doi.org/10.1177/1078155210381287

[44] O'DEA D, HANDY CM, WEXLER A. Ocular changes with oxaliplatin. Clin J Oncol Nurse 2006; 10: 227-229. http:// dx.doi.org/10.1188/06.CJON.227-229

[45] MESQUIDA M, SANCHEZ-DALMAU B, ORTIZ-PEREZ S, PELEGRIN L, MOLINA-FERNANDEZ JJ et al. Oxaliplatinrelated ocular toxicity. Case Rep Oncol 2010; 3: 423-427. http://dx.doi.org/10.1159/000322675

[46] BERRETTA M, TAIBI R, BEARZ A, LA MURA N, BERRETTA $S$ et al. Dysphonia as an unusual toxic event of oxaliplatin-based chemotherapy. J Chemother 2004; 16: 595-598. http://dx.doi.org/10.1179/joc.2004.16.6.595

[47] SHAH A, UDWADIA ZF, ALMEL S. Oxaliplatin-induced lung fibrosis. Indian J Med Paediatr Oncol 2009; 30: 116-118. http://dx.doi.org/10.4103/0971-5851.64259

[48] WATKINS J, SLADE JH, PHAN A, ENG C, WEISSFERDT A et al. Fatal diffuse alveolar damage associated with oxaliplatin administration. Clin Colorectal Cancer 2011; 10: 198-202. http://dx.doi.org/10.1016/j.clcc.2011.03.019

[49] PROCHILO T, ABENI C, BERTOCCHI P, ZANIBONI A. Oxaliplatin-induced lung toxicity. Case report and review of the literature. Curr Drug Saf 2012; 7: 179-182. http://dx.doi. org/10.2174/157488612802715672

[50] ZEDAN AH, HANSEN TF, FEX SVENNINGSEN A, VILHOLM OJ. Oxaliplatin-induced neuropathy in colorectal cancer: many questions with few answers. Clin Colorectal Cancer 2014; 13: 73-80. http://dx.doi.org/10.1016/j.clcc.2013.11.004

[51] VELASCO R, BRUNA J. Chemotherapy-induced peripheral neuropathy: an unsolved issue. Neurologia 2010; 25: 116-131. http://dx.doi.org/10.1016/S0213-4853(10)70036-0 
[52] PACHMAN DR, BARTON DL, WATSON JC, LOPRINZI CL. Chemotherapy-induced peripheral neuropathy: prevention and treatment. Clin Pharmacol Ther 2011; 90: 377-387. http://dx.doi.org/10.1038/clpt.2011.115

[53] KUS T, AKTAS G, ALPAK G, KALENDER ME, SEVINC A et al. Efficacy of venlafaxine for the relief of taxane and oxaliplatin-induced acute neurotoxicity: a single-center retrospective case-control study. Support Care Cancer 2015 [Epub ahead of print].

[54] MUKHERJEE N, CARROLL BL, SPEES JL, DELAY ER. Pre-treatment with amifostine protects against cyclophosphamide-induced disruption of taste in mice. PLoS ONE 2013; doi: 10.1371/journal.pone. 0061607.

[55] CERESA C, AVAN A, GIOVANETTI E, GELDOF AA, AVAN $A$ et al. Characterization of and protection from neurotoxicity induced by oxaliplatin, bortezomib and epothilone-B. Anticancer Res 2014; 34: 517-523.

[56] SALEHI Z, ROAYAEI M. Effect of vitamin E on oxaliplatin-induced peripheral neuropathy prevention: A randomized controlled trial. Int J Prev Med 2015; doi: 10.4103/2008-7802.169021. http://dx.doi. org/10.4103/2008-7802.169021

[57] SAIF MW, REARDON J. Management of oxaliplatin-induced peripheral neuropathy. Ther Clin Risk Manag 2005; 1: 249 258.

[58] HAN CH, KHWAOUNJOO P, KILFOYLE DH, HILL A, MCKEAGE MJ. Phase I drug-interaction study of effects of calcium and magnesium infusions on oxaliplatin pharmacokinetics and acute neurotoxicity in colorectal cancer patients. BMC Cancer 2013; doi: 1186/1471-2407-13-495. 